Original Article (short paper)

\title{
Differences in motor control of an aiming task in different group ages of the elderly

\author{
Lucas S. Figueiredo ${ }^{1}$, Tércio Apolinário-Souza ${ }^{1}$, Natália Lelis-Torres ${ }^{1}$, Guilherme M. Lage ${ }^{1}$, Herbert Ugrinowitsch ${ }^{1}$ \\ ${ }^{1}$ Universidade Federal de Minas Gerais, UFMG, Escola de Educação Física, \\ Fisioterapia e Terapia Ocupacional, Belo Horizonte, MG, Brazil
}

\begin{abstract}
Aims: This study aimed to investigate how different age groups of older adults perform and control movements in a goal-directed aiming task and the importance of visual feedback during these movements. Methods: Participants included 22 old adults, divided in two age groups: younger (60-70 yr) and older (80-90 yr). Subjects performed the task in a condition with vision and in a condition where vision was deprived. Results: In the vision condition, younger subjects showed smaller movement and reaction times, smaller radial errors, higher peak velocities, lower relative times to reach peak velocity than older subjects. In the vision-deprived condition the same results were found, except for radial error measure, where no significant effect for age groups was found. Conclusion: Younger subjects seemed to rely more on visual online feedback than older subjects and older subjects use other sensory sources to meet the possible deficits of information obtained by vision.
\end{abstract}

Keywords: aging, motor control, aiming, visual feedback.

\section{Introduction}

In goal-directed manual aiming tasks that involve both speed and accuracy, older adults are slower than younger adults. Decreasing in both central ${ }^{1,2,3}$ and peripheral functions $\mathrm{s}^{4,5}$, as well as alterations in musculoskeletal and sensory system underlie the high reaction and movement time observed in the elderlies ${ }^{4,5}$. A complementary explanation is that older adults ascribe more emphasis to responding accurately than quickly. Thus, older adults assure their accuracy by moving slower than young adults $^{6}$. This trade-off produces lower peak velocity and larger acceleration and deceleration times s,8,9 $^{7}$.

An increased number of online adjustments is also observed in older adults, presumably as a result of the sensory-motor changes related to aging ${ }^{10}$. The online adjustments are corrective processes, which ascribe spatial accuracy and relies on visual information ${ }^{11}$. If older adults emphasizes accuracy over speed increasing the corrective processes, the visual information during the movement execution should affect more their aiming performance than in younger adults. Aiming movements to a fixed target are composed by an initial impulse phase, characterized by a ballistic movement, open-loop controlled, that brings the limb near the target, and an online control phase, closed-loop controlled, with adjustments visually guided in the last portion of the movement ${ }^{12}$. Adopting this two sub-movements theoretical framework, we can expect more reliance of the online control phase to the older adults compared to the adults.

The distribution of the two sub-movements is affected by the relationship between age and index of task difficulty (ID) ${ }^{13}$. When ID is manipulated via target distance, both initial impulse and online control phases are affected. If ID is manipulated by changing width of the target, only online control phase is impacted ${ }^{14,13}$. With regards to aging, an increased ID resulting from the manipulation of the size of the target impacts more on the online control phase in older adults than in young adults ${ }^{13}$. This finding indicates different age-related control strategies to task ID.

Manual aiming studies have used young adults as a control to investigate the motor control in older adults. However, our knowledge about the continuous changes in sensorimotor system acting on manual aiming during aging is still limited. The expression of the manual aiming control throughout aging and its relation with task constraints need to be investigated. Therefore, this study aimed to investigate the manual aiming control in different group ages of the elderly. Two experiments were carried out. In the first experiment, participants practiced the aiming task with two different ID. The two ID were manipulated via the size of the target. We hypothesized that younger participants would be faster than older participants for reaction and movement times, consequently older participants would present the same level of accuracy than the youngers. Moreover, younger participants would present higher level of peak velocity, higher relative peak of velocity (indicating longer initial impulse phase) and fewer number of online corrections. In relation to the two different ID, the hypothesis is that an increased ID will impacts more on the online control phase to the older participants than to the younger participants. In the second experiment, participants practiced the aiming task with the two ID without visual information about the target and the performing arm. We expected a greater reliance on online visual feedback for older subjects. Therefore, older participants would present worse accuracy and longer initial impulse phase 
indicating a higher reliance of pre-planning due to the absence of visual information.

\section{Experiment 1}

\section{Methods}

\section{Participants}

Twenty-two subjects participated in the study (18 women and 4 men) in two groups: younger old (YOG) ranging in age from 60 to 70 years ( 11 subjects, age $=64.7 \pm 2.4$ years , and older old (OOG) ranging in age from 80 to 90 years ( 11 subjects, age $=82.7$ \pm 1.5 years). The participant groups were recruited from a physical activity project at the Universidade Federal de Minas Gerais. The duration of the subjects' previous participation in the physical activity program was not controlled for; however, all subjects were participating in the program during the experimental period.

The inclusion criteria were obtaining a score equal to or higher than 24 points in a Mini-mental exam (in cases of less than 4 years of education, the cutting point moved to 17 instead of 24), presenting no type of pain or neurological and/or musculoskeletal disease at the time of the experiment (self-declared), and having normal or corrected-to-normal visual acuity in both eyes. All participants were right-handed (mean laterality quotient $=100$; Edinburgh Handedness Inventory $\left.{ }^{15}\right)$. The general characteristics of these groups are summarized in Table 1.

The UFMG Ethics Committee approved all the procedures, and the subjects signed an informed consent form after receiving a full explanation of the study (protocol number 49546215.3.0000.5149).

Table 1. Participants Characteristics

\begin{tabular}{ccc}
\hline Characteristic & Younger old (YOG) & Older old (OOG) \\
\hline Male/female & $2 / 9$ & $2 / 9$ \\
Age (years) & $64.7 \pm 2.4$ & $82.7 \pm 1.5$ \\
MMSE score & $27.5 \pm 1.4$ & $25.1 \pm 2.3$ \\
Education (years) & $12.6 \pm 3.0$ & $5.3 \pm 3.1$ \\
Oldfield score & 100 & 100 \\
\hline
\end{tabular}

Note: Results are presented as the mean and confidence interval. MMSE $=$ Mini-Mental State Examination. Oldfield scores indicate handedness ( -100 : extremely left-handed, +100 : extremely right-handed). All participants answered $100 \%$ in Oldfield, so there is no confidence interval.

\section{Apparatus and Task}

The manual aiming movements were quantified using a commercial digitizing tablet and the MovAlyzeR software (NeuroScript, LLC; Tempe, AZ, USA). We used a non-inking pen with a Wacom Intuos 3 digitizing tablet $(30.4 \mathrm{~cm}$ x $30.4 \mathrm{~cm}$, RMS accuracy $0.01 \mathrm{~cm}$ ). The sampling rate was $200 \mathrm{~Hz}$. The tablet was attached to an MS Windows laptop computer (15.4" diagonal widescreen) running the MovAlyzeR software. The distance traveled by the non-inking pen on the tablet was proportional to the distance traveled by the cursor on the computer screen.

The motor task was similar to some previous tasks used in aiming studies (e.g. Lage, Malloy-Diniz, Neves, Gallo, Valentini, Corrêa $^{16}$, Lage et al. ${ }^{17}$ ), whose motor task consisted of executing a goal-directed manual movement with a non-inking pen on a digitizing tablet.

\section{Procedure}

The participants were seated comfortably in a chair in front of the digitizing tablet and were required to make fast and accurate strokes with the pen from the home position to the target. The home position was positioned centrally and at the bottom of the monitor. The participant was instructed to align the medial part of their body with the home position. A continuous trace of the pen's movement was displayed in real time, indicating to the performer the trajectory of his/her stroke.

The trial started with a presentation of both the home position and the circular target (the pre-cue) on the monitor. The participant placed the cursor on the home position during this pre-cue period. Then, the target disappeared from the screen, in a random interval ranging from 2 to $3 \mathrm{~s}$. The target turned into an imperative stimulus that would instruct the participants "go"; at this point, the recording of the trial began. The participant was instructed to complete the movement to the target as quickly and as accurately as possible.

Two conditions of index of difficulty were presented for subjects, low and high. In the low index of difficulty (LID), the target (1 cm in diameter) was presented at a distance of $19 \mathrm{~cm}$ center-to-center and at an angle of $45^{\circ}$ from the upper right of the screen from the home position, resulting in an index of difficulty of 5.2 bits $^{18}$. In the high index of difficulty (HID), the target $(0.5$ $\mathrm{cm}$ in diameter) was presented at a distance $19 \mathrm{~cm}$ center-to-center and at an angle $45^{\circ}$ from the upper right of the screen from the home position, resulting in an index of difficulty of $6.2 \mathrm{bits}^{18}$.

Each subject participated in a single experimental session. At the start of each session, a demonstration of the task and instructions were provided. In addition, the subject then performed 20 trials for familiarization with the task. Within the familiarization, 10 trials were performed randomly for each condition (LID and HID). Following familiarization, 5 trials of each condition were performed. Each trial alternated between each condition (LID and HID). These 10 trials were used for analysis.

Assessment and Dependent Variables

The pen movements were low-pass-filtered at $12 \mathrm{~Hz}$ using a Fast Fourier Transform (FFT) and were differentiated to yield estimates of the velocity and acceleration curves. Each stroke was segmented into primary and secondary submovements by the first negative-to-positive zero crossing after the absolute peak 
velocity in the acceleration profile.

The performance measures examined were reaction time (RT), movement time (MT) and radial error (RE). The RT was the time in seconds (s) from the beginning of the imperative stimulus until the beginning of the stroke. The beginning and the end of the MT were the first and last sample, respectively, where the absolute vertical velocity exceeded or fell below $5 \%$ of the absolute peak velocity and reached the instrument noise level ${ }^{19}$. The radial error general accuracy measure accounts for two-dimensions ( $\mathrm{x}$ and y axes). Radial error was calculated by measuring the lengths of the horizontal and vertical errors, squaring both, and taking the square root of the added squared $\mathrm{x}$ and $\mathrm{y}$ values.

The kinematic measures analyzed were as follows: peak velocity (PV), relative time to peak velocity (RTPV) and number of discontinuities in the acceleration of the secondary submovement (ND). The duration of the primary submovement and PV measures related to the preprogramming part of the movement ${ }^{20}$. The primary submovement was considered to be from the movement onset to the first negative-to-positive point (or second zero-crossing) of the acceleration profile after the peak velocity. The secondary submovements were subsequent zero-crossings in the acceleration profile. Thus, the ND reflects online modification to the movement trajectory based on sensory information regarding the movement error. The RTPV measure reflects the type of strategy involved in the planning and execution of the movements ${ }^{12}$ (FIGURE 1).

Figure 1.

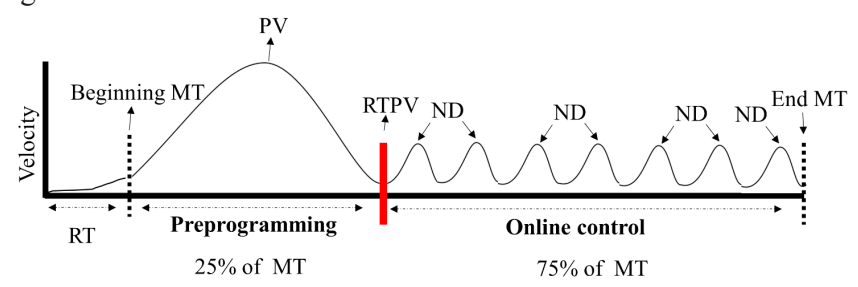

Note: Hypothetical data. Reaction time (RT), movement time (MT), peak velocity (PV), relative time to peak velocity (RTPV) and number of discontinuities in the acceleration of the secondary submovement (ND).

The estimation of handwriting performance and kinematic variables was conducted automatically by the MovAlyzeR software.

\section{Data and Statistical Analysis}

To check data for possible differences and interactions between groups for the two conditions, a mix-model ANOVA ( 2 groups [younger elderly, older elderly] by 2 indices of difficulty [high, low]) was used to analyze all variables. The Tukey test was adopted for post hoc comparisons. An alpha level of .05 was set for all statistical tests and effect sizes were calculated by eta-squared $\left(\mathrm{n}^{2}\right)$. The data obtained were organized in blocks of 5 trials, representing the mean value of the analyzed trials for each ID condition. All analyses were conducted using Statistica software package version 10 (Statsoft, Tulsa, OK).

\section{Results}

\section{Performance Measures}

RT analysis detected a main effect for age groups, $\mathrm{F}(1,44)$ $=29.01, \mathrm{p}<.001, \mathrm{\eta}^{2}=.39$, with smaller times for the YOG $(558 \mathrm{~ms})$ than for the OOG $(671 \mathrm{~ms})$. The analysis showed no significant effect for ID, $\mathrm{F}(1,44)=.00, \mathrm{p}>.96, \mathrm{\eta}^{2}=.00$; or for interaction, $\mathrm{F}(1,44)=.00, \mathrm{p}>.45, \mathrm{\eta}^{2}=.01$.

MT analysis detected a main effect for age groups, $\mathrm{F}(1,44)$ $=15.86, \mathrm{p}<.001, \mathrm{\eta}^{2}=.26$, with smaller times for the YOG $(1.77 \mathrm{~s})$ than for the OOG $(1.99 \mathrm{~s})$. The analysis showed no significant effect for ID, $\mathrm{F}(1,44)=2.52, \mathrm{p}>.11, \eta^{2}=.05$; or for interaction, $\mathrm{F}(1,44)=1.41, \mathrm{p}>.24, \mathrm{\eta}^{2}=.03$.

$\mathrm{RE}$ analysis detected a main effect for age groups, $\mathrm{F}(1,44)$ $=7.13, \mathrm{p}<.008, \eta^{2}=.14$, with smaller errors for the YOG $(0.23 \mathrm{~cm})$ than for the OOG $(1.23 \mathrm{~cm})$. The analysis showed no significant effect for ID, $\mathrm{F}(1,44)=.03, \mathrm{p}>.84, \mathrm{n}^{2}=.00$; or for interaction, $\mathrm{F}(1,44)=.10, \mathrm{p}>.75, \mathrm{\eta}^{2}=.00$.

Kinematic Measures

PV analysis detected a main effect for age groups, $F(1,44)$ $=17.24, \mathrm{p}<.001, \eta^{2}=.28$, with higher velocities for the YOG $(9.77 \mathrm{~cm} / \mathrm{s})$ than for the OOG $(6.08 \mathrm{~cm} / \mathrm{s})$. The analysis showed no significant effect for ID, $\mathrm{F}(1,44)=.21, \mathrm{p}>.64, \mathrm{\eta}^{2}=.00$; or for interaction, $\mathrm{F}(1,44)=.02, \mathrm{p}>.86, \mathrm{\eta}^{2}=.00$.

RTPV analysis detected a main effect for age groups, $\mathrm{F}(1,44)=14.89, \mathrm{p}<.001, \mathrm{\eta}^{2}=.25$, with lower relative times to reach peak velocity for the YOG $(20 \%)$ than for the OOG (30\%). The analysis showed no significant effect for ID, $\mathrm{F}(1,44)=.94, \mathrm{p}>.33, \mathrm{\eta}^{2}=.02$; or for interaction, $\mathrm{F}(1,44)=$ $.98, \mathrm{p}>.32, \mathrm{\eta}^{2}=.02$.

ND analysis showed no significant effect for age groups, $\mathrm{F}(1,44)=.06, \mathrm{p}>.79, \mathrm{\eta}^{2}=.00 ; \mathrm{ID}, \mathrm{F}(1,44)=1.50, \mathrm{p}>.22$, $\mathrm{\eta}^{2}=.03$; or interaction, $\mathrm{F}(1,44)=.04, \mathrm{p}>.83, \mathrm{\eta}^{2}=.00$.

Table 2. Results of Experiment 1

\begin{tabular}{ccccccc}
\hline & \multicolumn{2}{c}{ With Vision } & Value & $\mathbf{p}$ & $\mathbf{\eta}^{\mathbf{2}}$ & \\
\hline YOG & OOG & & & & \\
RT (s) & 0.55614 & 0.67183 & & & & \\
& & & F $=29,01$ & $<0.001$ & 0.39 & 0.99 \\
\hline
\end{tabular}




\begin{tabular}{|c|c|c|c|c|c|c|}
\hline A & 0.582555 & 0.665088 & & & & \\
\hline & & & $\mathrm{F}=.00$ & n.s. & 0.00 & 0.05 \\
\hline B & 0.59284 & 0.664073 & & & & \\
\hline \multirow[t]{2}{*}{ MT (s) } & 1.775136 & 1.995799 & & & & \\
\hline & & & $F=15.86$ & $<0.001$ & 0.27 & 0.97 \\
\hline \multirow[t]{2}{*}{ A } & 1.852445 & 1.941079 & & & & \\
\hline & & & $F=2.52$ & n.s. & 0.05 & 0.34 \\
\hline B & 1.697827 & 1.953178 & & & & \\
\hline \multirow[t]{2}{*}{$\mathrm{RE}$} & 0.237791 & 1.237998 & & & & \\
\hline & & & $F=7.13$ & $<0.01$ & 0.14 & 0.76 \\
\hline \multirow[t]{2}{*}{ A } & 0.280546 & 1.37026 & & & & \\
\hline & & & $\mathrm{F}=.03$ & n.s. & 0.00 & 0.05 \\
\hline B & 0.19 & 1.10 & & & & \\
\hline \multirow[t]{2}{*}{$\mathrm{PV}(\mathrm{cm} / \mathrm{s})$} & 9.772691 & 6.080756 & & & & \\
\hline & & & $F=17.24$ & $<0.001$ & 0.28 & 0.98 \\
\hline \multirow[t]{2}{*}{ A } & 9.641812 & 5.80324 & & & & \\
\hline & & & $\mathrm{F}=.21$ & n.s. & 0,00 & 0.07 \\
\hline B & 9.90357 & 6.822488 & & & & \\
\hline \multirow[t]{2}{*}{ RTPV (\%) } & 20 & 30 & & & & \\
\hline & & & $F=14.89$ & $<0.001$ & 0,25 & 0.96 \\
\hline \multirow[t]{2}{*}{ A } & 20 & 32 & & & & \\
\hline & & & $\mathrm{F}=.94$ & n.s. & 0.02 & 0.15 \\
\hline B & 20 & 31 & & & & \\
\hline \multirow[t]{2}{*}{ ND } & 9.037917 & 9.198333 & & & & \\
\hline & & & $\mathrm{F}=.06$ & n.s. & 0.00 & 0.05 \\
\hline \multirow[t]{2}{*}{ A } & 9,35 & 9,641667 & & & & \\
\hline & & & $F=1.50$ & n.s. & 0.03 & 0.22 \\
\hline B & 9.11 & 9.11 & & & & \\
\hline
\end{tabular}

\section{Discussion}

Considering the differences between different age groups within the elderly, and their implications for the control of movements of these individuals, this study aimed to investigate the performance and kinematics of different age groups within the elderly in a goal-directed aiming task. Our results show that different age groups within the elderly produce movements with distinct overall performance and kinematics, in that older elderly subjects generally showed worse performance than younger elderly subjects.

It was hypothesized that increasing age would be associated with higher times to initiate and carry out movements, similar accuracy to younger elderly subjects, lower and earlier PV and higher ND. This hypothesis has not been entirely confirmed because the ND did not differ between groups and the PV of younger subjects was earlier than that of the older subjects. The higher MT, RT, RTPV and RE stem from neural changes resulting from increasing age, as a result of slowness to transmit signals into the spinal cord track ${ }^{21}$, death of Alpha motor neurons in the spinal cord, and degeneration of cortical motor neurons ${ }^{22}$ among other factors. Such changes cause deficits in planning and motor execution and reduce accuracy ${ }^{23}$. However, some studies failed to show differences in the afore mentioned performance measures ${ }^{24,11,10}$. As stated previously, most studies that aimed to report differences between young adults and older adults used a broad age group of older adults, not taking into account differences between their respective states in life. Thus, extensive age range is possibly a confounding variable that must be accounted for in studies.

It was also hypothesized that overall differences between the different age groups would be accentuated with increasing ID, especially on the online control phase of the older participants. However, there were no differences between the groups according to the different ID's in any of the measures. That is, regardless of age, the target size was not able to influence the behavior of the subjects. This probably happened due to a relatively long time relying on online feedback by both groups. One possibility 
for inferring the dependence on online feedback is through the division of the aiming movement in two submovements. The first submovement is characterized by an initial pulse more associated with the central control, and the second submovement is characterized by the online control that would be more associated with the online feedback ${ }^{25}$. In general, previous studies indicate that the elderly spend more time in the second submovement than younger adults (see Temprado, Sleimen-Malkoun, Lemaire, Rey-Robert, Retornaz, Berton ${ }^{13}$ ). This strategy allows more time to process the information from online feedback. This longer time used to process online feedback allowed participants from both groups to perform effective corrections without compromising performance due to ID conditions.

This proposition is supported by comparing the results of the present study with previous studies on young adults. In previous studies it is possible to observe a trend that $50 \%$ of the movement time is intended for online feedback use $e^{26,27,28}$. However, in this study, the groups spent an average of $75 \%$ of the movement time for online feedback use.

Contrary to the study proposition, ND analysis showed no significant effect for age groups. Some studies have shown that in tasks requiring online visual corrections, the elderly tend to produce the same ND, but spend a longer time performing these corrections ${ }^{13}$. Spending longer times performing these corrections results in an efficient use of online feedback to maintain accuracy level $^{29}$. In our study, although the younger subjects showed higher accuracy than older subjects, the same ND was used. Thus, the younger subjects produced more efficient corrections. In summary, the results showed that in elderly subjects, the older relied less on online feedback than the younger did, contrary to what was expected. One way to test this claim is to deprive the subjects of visual online feedback. If older subjects really rely less on visual feedback in this task, then it is expected that their performance would not be as affected as of the younger subjects when deprived of vision. But if older subjects rely more on visual feedback, as it would be expected, then their performance will be even worse than of the younger subjects when deprived of vision.

\section{Experiment 2}

\section{Methods}

\section{Participants}

The same participants of experiment 1 were used in experiment 2 .

\section{Apparatus and Task}

The same apparatus and task of experiment 1 were used in experiment 2 .

\section{Procedure}

After participants finished experiment 1, they began experiment 2 . The same procedures of experiment 1 were used in experiment 2. However, to occlude vision of the continuous trace of the pen's movement, the trajectory was not displayed in real time to the participant on his/her monitor. In addition, an apparatus was placed over the tablet with adequate space provided to allow unrestricted movement. This allowed occlusion of vision of the limb in this experiment.

\section{Assessment and Dependent Variables}

The same assessment and dependent variables of experiment 1 were used in experiment 2.

\section{Data and Statistical Analysis}

The same data and statistical analysis of experiment 1 were used in experiment 2 .

\section{Results}

\section{Performance Measures}

RT analysis detected a main effect for age groups $\mathrm{F}(1,44)=$ $9.36, \mathrm{p}<.003, \mathrm{n}^{2}=.17$, with smaller times for the YOG $(619 \mathrm{~ms})$ than for the OOG $(691 \mathrm{~ms})$. The analysis showed no significant effect for $\operatorname{ID~} \mathrm{F}(1,44)=.01, \mathrm{p}>.91, \mathrm{\eta}^{2}=.00$, or for interaction, $\mathrm{F}(1,44)=.00, \mathrm{p}>.95, \mathrm{\eta}^{2}=.00$.

MT analysis detected a main effect for age groups $\mathrm{F}(1,44)$ $=4.84, \mathrm{p}<.03, \mathrm{\eta}^{2}=.09$, with lower times for the YOG $(1.70 \mathrm{~s})$ than for the OOG $(1.92 \mathrm{~s})$. The analysis showed no significant effect for ID $\mathrm{F}(1,44)=.00, \mathrm{p}>.98, \mathrm{\eta}^{2}=.00$, or for interaction $\mathrm{F}(1,44)=.00, \mathrm{p}>.80, \mathrm{\eta}^{2}=.00$.

$\mathrm{RE}$ analysis showed no significant effect for age groups $\mathrm{F}(1,44)=.23, \mathrm{p}>.62, \mathrm{\eta}^{2}=.00$, ID $\mathrm{F}(1,44)=.01, \mathrm{p}>.90, \mathrm{\eta}^{2}=$ .00 , or interaction $\mathrm{F}(1,44)=.74, \mathrm{p}>.39, \mathrm{\eta}^{2}=.01$.

\section{Kinematic Measures}

PV analysis detected a main effect for age groups, $\mathrm{F}(1,44)$ $=10.26, \mathrm{p}<.002, \mathrm{\eta}^{2}=.18$, with higher velocities for the YOG $(8.50 \mathrm{~cm} / \mathrm{s})$ than for the OOG $(5.61 \mathrm{~cm} / \mathrm{s})$. The analysis showed no significant effect for ID, $\mathrm{F}(1,44)=.52, \mathrm{p}>.47, \mathrm{\eta}^{2}=.01$; or for interaction, $\mathrm{F}(1,44)=.67, \mathrm{p}>.41, \mathrm{n}^{2}=.01$. 
RTPV analysis detected a main effect for age groups, $\mathrm{F}(1,44)$ $=5.39, \mathrm{p}<.02, \mathrm{\eta}^{2}=.10$, with lower relative times to reach peak velocity for the YOG $(22 \%)$ than for the OOG $(30 \%)$. The analysis showed no significant effect for ID, $F(1,44)=.80, p>$
$.37, \eta^{2}=.01$; or for interaction, $\mathrm{F}(1,44)=.02, \mathrm{p}>.88, \mathrm{\eta}^{2}=.00$.

$\mathrm{ND}$ analysis showed no significant effect for age groups, $\mathrm{F}(1,44)=.16, \mathrm{p}>.88, \mathrm{\eta}^{2}=.00 ; \mathrm{ID}, \mathrm{F}(1,44)=.31, \mathrm{p}>.57, \mathrm{\eta}^{2}=$ .00 ; or interaction, $\mathrm{F}(1,44)=.02, \mathrm{p}>.88, \mathrm{\eta}^{2}=.00$.

Table 3. Results of Experiment 2

\begin{tabular}{|c|c|c|c|c|c|c|}
\hline & \multicolumn{2}{|c|}{ With Vision } & \multirow[t]{2}{*}{ Value } & \multirow[t]{2}{*}{$\mathbf{p}$} & \multirow[t]{2}{*}{$\eta^{2}$} & \multirow[t]{2}{*}{$\alpha$} \\
\hline & YOG & OOG & & & & \\
\hline \multirow[t]{2}{*}{$\mathrm{RT}(\mathrm{s})$} & 0.61911 & 0.691982 & & & & \\
\hline & & & $F=9.36$ & $<0.01$ & 0.17 & 0.84 \\
\hline \multirow[t]{2}{*}{ A } & 0.618497 & 0.725342 & & & & \\
\hline & & & $\mathrm{F}=.01$ & n.s. & 0.00 & 0.05 \\
\hline B & 0.619723 & 0.693955 & & & & \\
\hline \multirow[t]{2}{*}{ MT (s) } & 1.701557 & 1.921852 & & & & \\
\hline & & & $F=4.84$ & $<0.01$ & 0.09 & 0.57 \\
\hline \multirow[t]{2}{*}{ A } & 1.713003 & 1.908992 & & & & \\
\hline & & & $\mathrm{F}=.00$ & n.s. & 0.00 & 0.05 \\
\hline B & 1.69011 & 1.900212 & & & & \\
\hline \multirow[t]{2}{*}{$\mathrm{RE}$} & 0.94301 & 1.492589 & & & & \\
\hline & & & $\mathrm{F}=.23$ & n.s. & 0.00 & 0.07 \\
\hline \multirow[t]{2}{*}{ A } & 1.33 & 1.48 & & & & \\
\hline & & & $\mathrm{F}=.01$ & n.s. & 0.00 & 0.05 \\
\hline B & 0.55 & 1.50 & & & & \\
\hline \multirow[t]{2}{*}{$\mathrm{PV}(\mathrm{cm} / \mathrm{s})$} & 8.505599 & 5.614058 & & & & \\
\hline & & & $F=10.26$ & $<0.01$ & 0.84 & 1.0 \\
\hline \multirow[t]{2}{*}{ A } & 11.28016 & 6.346448 & & & & \\
\hline & & & $\mathrm{F}=.52$ & n.s. & 0.01 & 0.10 \\
\hline B & 9.851695 & 6.483462 & & & & \\
\hline \multirow[t]{2}{*}{ RTPV (\%) } & 22 & 30 & & & & \\
\hline & & & $F=5.39$ & $<0.01$ & 0.10 & 0.62 \\
\hline \multirow[t]{2}{*}{ A } & 21 & 33 & & & & \\
\hline & & & $\mathrm{F}=.80$ & n.s. & 0.01 & 0.14 \\
\hline B & 24 & 33 & & & & \\
\hline \multirow[t]{2}{*}{ ND } & 8.958333 & 9.075 & & & & \\
\hline & & & $\mathrm{F}=.16$ & n.s. & 0.00 & 0.05 \\
\hline \multirow[t]{2}{*}{ A } & 8.8 & 8.8 & & & & \\
\hline & & & $\mathrm{F}=.31$ & n.s. & 0.00 & 0.08 \\
\hline B & 9.11 & 9.35 & & & & \\
\hline
\end{tabular}

Note: Results are presented as the mean. n.s. = no significant difference . A and B represent the high and low indices of difficulty, respectively.

\section{Discussion}

Experiment 2 aimed to examine the influence of different age groups within the elderly on accuracy and kinematics in a goal-directed aiming task, without the availability of visual online feedback. The results of this study showed that the age groups of elderly produced goal-directed aiming movements with different performances and kinematics.

We raised the hypothesis that in the absence of online visual feedback, the differences between the different age groups of elderly would be accentuated. Older subjects would depend more on online visual feedback, so their performance and kinematic characteristics would be dramatically worse when deprived of online visual feedback. The hypothesis was partially confirmed as the ND and the RE did not differ between groups, and the RTPV was earlier in younger than in older subjects. However, as hypothesized, RT, MT and PV measures for the younger participants showed smaller values than for the older ones. 
The results shown in temporal performance and kinematic measures such as RT, MT and PV are supported by the literature when comparing young and older adults ${ }^{11,30}$. However, the groups did not differ in terms of special performance accuracy (RE). It can be speculated that it is more difficult to integrate visual information with movement for older subjects ${ }^{31}$. Because of this, older participants use central control of movements as a primary movement control strategy rather than online feedback. Thus, when deprived of sight, performance does not suffer to the same extent as for the younger elderly in terms of accuracy. The performance of older elderly subjects does not suffer to the same extent due to less dependence on online visual feedback. This assertion is supported by evaluation of the RTPV in this study. We found that older subjects "spent" a smaller portion of the MT in the second submovement $(70 \%)$ than younger subjects (78\%). In summary, the results suggest that older individuals seemed to prioritize the spatial goal of the task (seen in radial error measures), which resulted in greater movement times but also allowed spatial accuracy to be similar to younger subjects.

\section{General Discussion}

This study aimed to investigate the influence of different age groups within the elderly on performance and kinematic characteristics in a goal-directed aiming task with and without vision. Two experiments were carried out. The first experiment aimed to investigate the preferred strategies of each age group when vision was available. The second experiment aimed to investigate the role of online visual feedback in the movement performance and kinematic profiles of different age groups through visual withdrawal. We hypothesized that the older subjects would be more dependent on online feedback control in both vision conditions. The above proposition was not supported, since: the older elderly subjects had lower RTPV than the younger subjects in both experiments; and in the vision withdrawal condition, younger subjects had similar performance accuracy to the older subjects, which was not observed in the first experiment. That is, when vision was available, the younger subjects had lower RE than the older subjects, but this difference was not observed when vision was unavailable. This indicates that younger subjects were in fact most affected by the vision withdrawal in terms of accuracy.

Performance measures such as MT, RT and PV were not expected to be those most affected by the vision withdrawal. Once the vision withdrawal was conducted, the task demand lies mainly on spatial aspects (seen in radial error measures), which justifies changes in special measures such as RE. Since 1899 it has been known that when subjects close their eyes and perform a task with moderate speed, losses in accuracy occur ${ }^{25}$.

RE did not differ between younger and older elderly subjects when compared in the second experiment. Some studies have also found no difference in accuracy measures between young adults and older adults with vision withdrawal. For example, Baweja, Kwon, Onushko, Wright, Corcos, $\mathrm{Christou}^{32}$ found that increasing the error related to accuracy was not associated with increasing age when practitioners were deprived of vision. Lyons, Elliott, Swanson, Chua ${ }^{11}$ also found that a group of older adults did not differ from younger adults in accuracy measurements when vision was withdrawn. The maintenance of performance accuracy in the oldest subjects without vision is presumably due to a greater use of proprioceptive information. The effectiveness of movements in online feedback control comes from proprioception and vision ${ }^{32,5,33}$. However, in experiment 2 most of the visual information about the target and effector members was suppressed, leading to greater reliance on proprioceptive information, as suggested by many authors ${ }^{34,7,35}$.

This reorganization of sensory sources can be seen in other age groups, as proposed by Hay, Bard, Ferrel, Olivier, Fleury ${ }^{36}$ According to the authors, children under 5 years old use less visual information than 7 and 9 year-old children do. In contrast, from 7 to 9 years old there is a greater reliance on visual information. However, at the age of 11 a smaller reliance on visual information is observed ${ }^{36}$. Thus, a reorganization of the relevance of afferent information abstracted through different sensory sources may occur in parallel to the aging process. Hence, with increasing age there would be an increasing relevance of proprioceptive information compared with visual information.

\section{Conclusion}

In conclusion, our results show that older elderly subjects perform more poorly than younger ones in goal-directed movements that require both speed and accuracy. It was also shown that in regard to the elderly, contrary to expectations, older individuals do not rely more on visual online feedback to carry out goal-directed movements than younger individuals. Therefore, the differences in older individuals motor performance cannot be attributed solely to age-related differences in visual feedback use but also to the use of proprioceptive feedback.

More importantly, we provide evidence that in different age groups of the elderly there are differences in integration of visual information during the execution of movement. In this case, specifically, we hypothesized that older individuals use other sensory sources to meet the possible deficits of abstracted information obtained by vision. We suggest, however, that more studies should be carried out in order to confirm this hypothesis.

\section{References}

1. Cerella, J. Information processing rates in the elderly. Psychol Bull. 1985; 98(1): 67-83. doi:10.1037/0033-2909.98.1.67

2. Ketcham CJ, Seidler RD, Van Gemmert AW, Stelmach GE. Age-related kinematic differences as influenced by task difficulty, target size, and movement amplitude. J Gerontol B Psychol. 2002; 57: 54-64.

3. Trewartha KM, Garcia A, Wolpert DM, Flanagan JR. Fast But Fleeting: Adaptive motor learning processes associated 
with aging and cognitive decline. J Neurosci. 2014; 34(40): 13411-13421. doi:10.1523/JNEUROSCI.1489-14.2014.

4. Chen YT, Kwon M, Fox EJ, Christou EA. Altered activation of the antagonist muscle during practice compromises motor learning in older adults. J Neurophysiol. 2014; 112(4): 1010-1019. doi:10.1152/jn.00569.2013

5. Christou EA, Carlton LG. Age and contraction type influence motor output variability in rapid discrete tasks. J Appl Physiol (1985), 2002; 93(2): 489-498. doi:10.1152/ japplphysiol.00335.2001

6. Salthouse TA. Adult age and the speed-accuracy trade-off. Ergonomics. 1979; 22: 11-821.

7. Goggin NL, Meeuwsen HM, Goodwin JE. Effects of target size, movement amplitude, and vision on aiming movement control characteristics of older adults. Sport Exerc Psychol. 1993; 15: NASPSPA Abstract Supplement.

8. Van Halewyck F, Lavrysen A, Levin O, Boisgontier MP, Elliott D, Helsen WF. Factors underlying age-related changes in discrete aiming. Exp Brain Res, 2015; 233(6): 1733-1744. doi:10.1007/s00221-015-4247-3

9. Warabi T, Noda H, Kato T. Effect of aging on sensorimotor functions of eye and hand movements. Exp Neurol. 1986; 92(3): 686-697. doi:10.1016/0014-4886(86)90309-2

10. Poletti C, Sleimen-Malkoun R, Temprado JJ, Lemaire P. older and younger adults' strategies in sensorimotor tasks: insights from Fitts' pointing task. J Exp Psychol Hum Percept Perform. 2015; 41(2): 542-555. doi:10.1037/ xhp0000033

11. Lyons J, Elliott D, Swanson LR, Chua R. The use of vision in manual aiming by young and older adults. J Aging Phys Activ. 1996; 4(2): 165-178. doi:10.1123/japa.4.2.165

12. Elliott D, Helsen WF, Chua R. A century later: Woodworth's (1899) two-component model of goaldirected aiming. Psychol Bull. 2001 ; 127(3): 342-357. doi:10.1037//0033-2909.127.3.342

13. Temprado JJ, Sleimen-Malkoun R, Lemaire P, Rey-Robert B, Retornaz F, Berton E. Aging of sensorimotor processes: A systematic study in Fitts' task. Exp Brain Res. 2013; 228(1): 105-116. doi:10.1007/s00221-013-3542-0.

14. Rey-Robert B, Temprado JJ, Berton E. Aging and changes in complexity in the neurobehavioral system. Medicina (Kaunas). 2011; 47(1): 1-10

15. Oldfield RC. The assessment and analysis of handedness: the Edinburgh inventory. Neuropsychologia. 1971; 9: 97-113.

16. 16. Lage GM, Malloy-Diniz LF, Neves FS, Gallo LG, Valentini AS, Corrêa H. A kinematic analysis of manual aiming control on euthymic bipolar disorder. Psychiat Res. 2013; 208(2): 140-144. doi:10.1016/j. psychres.2012.09.046

17. 17. Lage GM, Miranda DM, Romano-Silva MA, Campos $\mathrm{SB}$, Albuquerque MR, Corrêa $\mathrm{H}$, et al. Association between the catechol-O-methyltransferase (COMT) Val158Met polymorphism and manual aiming control in healthy subjects. PloS One. 2014; 9(6): e99698. doi:10.1371/ journal.pone.0099698
18. Fitts PM. The information capacity of the human motor system in controlling the amplitude of movement. J Exp Psychol Gen. 1954; 47(6): 91-381. doi:10.1037/h0055392

19. Lage GM, Malloy-Diniz LF, Neves FS, de Moraes PHP, Corrêa H. A kinematic analysis of the association between impulsivity and manual aiming control. Hum Mov Sci. 2012; 31: 811-823. doi:10.1016/j.humov.2011.08.008

20. Khan M, Franks I, Elliott D, Lawrence G, Chua R, Bernier $\mathrm{P}$, et al. Inferring online and offline processing of visual feedback in target-directed movements from kinematic data. Neurosci Biobehav R. 2006; 30(8): 1106-1121. doi:10.1016/j.neubiorev.2006.05.002

21. Henderson CE, Phillips HS, Pollock RA, Davies AM, Lemeulle C, Armanini M, et al. GDNF: a potent survival factor for motoneurons present in peripheral nerve and muscle. Science. 1994; 266(5187): 1062-1064. doi:10.1126/science. 7973664

22. Roubenoff R. Sarcopenia and its implications for the elderly. Eur J Clin Nutr. 2000; 54 Suppl 3: S40-7. doi:10.1038/sj.ejcn.1601024

23. Shea CH, Park J, Braden HW. Related effects in sequential motor learning. Phys Ther. 2006; 86(4): 478-488.

24. Carnahan AA, Vandervoort LH. the influence of aging and target motion on the control of prehension. Exp Aging Res. 1998; 24(3): 289-306. doi:10.1080/036107398244265

25. Woodworth RS. The accuracy of voluntary movement. Psychol Rev. 1899; 3(2): 106.

26. Adam JJ, Nieuwenstein JH, Huys R, Paas FG, Kingma H, Willems $P$, et al. Control of rapid aimed hand movements: the one-target advantage. J Exp Psychol Hum Percept Perform. 2000; 26(1): 295-312. doi:10.1037/0096-1523.26.1.295

27. Elliott D, Calvert R. The influence of uncertainty and premovement visual information on manual aiming. Can J Psychol. 1990; 44(4): 501-511. doi:10.1080/14640748708401802

28. Elliott D, Allard F. The utilization of visual feedback information during rapid pointing movements. Q J Exp Psychol A. 1985; 37(3): 407-425. doi:10.1080/14640748508400942

29. Welsh TN, Higgins L, Elliott D. Are there age-related differences in learning to optimize speed, accuracy, and energy expenditure? Hum Movement Sci. 2007; 26(6): 892-912. doi:10.1016/j.humov.2007.04.004

30. Pratt J, Chasteen AL, Abrams RA. Rapid aimed limb movements: age differences and practice effects in component submovements. Psychol Aging. 1994; 9: 325-334.

31. Raz N, Rodrigue KM, Haacke EM. Brain aging and its modifiers: insights from in vivo neuromorphometry and susceptibility weighted imagings. Ann NY Acad Sci. 2009; 1097: 1-9. doi:10.1196/annals.1379.018

32. Baweja HS, Kwon M, Onushko T, Wright DL, Corcos DM, Christou EA. Processing of visual information compromises the ability of older adults to control novel fine motor tasks. Exp Brain Res. 2015; 233(12): 3475-3488. doi:10.1007/s00221-015-4408-4 
33. Heath M. Role of limb and target vision in the online control of memory-guided reaches. Motor Control. (2005); 9: 281-311.

34. Goble DJ, Coxon JP, Wenderoth N, Van Impe A, Swinnen SP. Proprioceptive sensibility in the elderly: Degeneration, functional consequences and plastic-adaptive processes. Neurosci Biobehav R. 2009; 33(3): 271-278. doi:10.1016/j. neubiorev.2008.08.012

35. Kalisch T, Kattenstroth J-C, Kowalewski R, Tegenthoff M, Dinse HR. Age-related changes in the joint position sense of the human hand. Clin Interv Aging. 2012; 7: 499-507. doi:10.2147/CIA.S37573

36. Hay L, Bard C, Ferrel C, Olivier I, Fleury M. Role of proprioceptive information in movement programming and control in 5 to 11-year old children. Hum Movement Sci. 2005; 24: 139-154. doi:10.1016/j.humov.2005.05.002

\section{Corresponding author}

Lucas S. Figueiredo

Escola de Educação Física, Fisioterapia e Terapia Ocupacional, Universidade Federal de Minas Gerais.

Av. Antônio Carlos, 6627, Pampulha, 31270-901, Minas Gerais, BRASIL.

Email: savassi88@hotmail.com

Manuscript received on October 25, 2017

Manuscript accepted on April 17, 2018

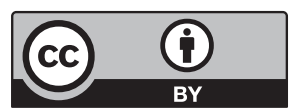

Motriz. The Journal of Physical Education. UNESP. Rio Claro, SP, Brazil - eISSN: 1980-6574 - under a license Creative Commons - Version 3.0 